\title{
Development and evaluation of an electropositive wellbore stabilizer with flexible adaptability for drilling strongly hydratable shales
}

\author{
Wei-An Huang ${ }^{1,2} \cdot$ Zheng-Song Qiu $^{1} \cdot$ Ming-Lei Cui ${ }^{3} \cdot \mathrm{Xin}_{\mathrm{Zhao}^{1}} \cdot$ \\ Jun-Yi Liu ${ }^{1}$ - Wei-Ji Wang ${ }^{1}$
}

Received: 25 August 2014/Published online: 18 July 2015

(c) The Author(s) 2015. This article is published with open access at Springerlink.com

\begin{abstract}
In order to overcome serious instability problems in hydratable shale formations, a novel electropositive wellbore stabilizer (EPWS) was prepared by a new approach. It has good colloidal stability, particle size distribution, compatibility, sealing property, and flexible adaptability. A variety of methods including measurements of particle size, Zeta potential, colloidal stability, contact angle, shale stability index, shale dispersion, shale swelling, and plugging experiments were adopted to characterize the EPWS and evaluate its anti-sloughing capacity and flexible adaptability. Results show that the EPWS has advantages over the conventional wellbore stabilizer (ZX-3) in particle size distribution, colloidal stability, inhibition, compatibility, and flexible adaptability. The EPWS with an average particle size of $507 \mathrm{~nm}$ and an average Zeta potential of $54 \mathrm{mV}$ could be stable for 147 days and be compatible with salt tolerant or positive charged additives, and it also exhibited preferable anti-sloughing performance to hydratable shales at 77,100 , and $120^{\circ} \mathrm{C}$, and better compatibility with sodium bentonite than ZX-3 and $\mathrm{KCl}$. The EPWS can plug micro-fractures and pores by forming a tight external mud cake and an internal sealing belt to retard pressure transmission and prevent filtrate invasion, enhancing hydrophobicity of shale surfaces by adsorption to inhibit
\end{abstract}

Wei-An Huang

masterhuang1997@163.com

1 School of Petroleum Engineering, China University of Petroleum, Qingdao 266580, Shandong, China

2 School of Mechanical and Chemical Engineering, The University of Western Australia, Crawley 6009, Australia

3 Shandong Shengli Vocational College, Dongying 257097, Shandong, China

Edited by Yan-Hua Sun hydration. The EPWS with flexible adaptability to temperature for inhibition and sealing capacity is available for long open-hole sections during drilling.

Keywords Shale $\cdot$ Wellbore stabilizer $\cdot$ Colloidal stability $\cdot$ Plugging $\cdot$ Hydrophobic modification

\section{Introduction}

The preservation of the wellbore stability has fundamental importance during oil and gas well drilling. About $75 \%$ of the side walls of oil and gas wellbores consist of shale and mud rocks, which are responsible for $90 \%$ of the wellbore instability problems (Corrêa and Nascimento 2005; Jiang et al. 2014; Wang et al. 2012a, b; Huang et al. 2007). Several types of shales with a significant amount of clay minerals are very reactive once they come into contact with water, and they can cause serious wellbore instability during drilling, like hole shrinkage and hole sloughing and caving (Hisham 2006; Wang et al. 2012a, b; Zhang et al. 2013a, b). Wellbore stability has been studied for a long time using mainly two quite different approaches. Some authors consider the problem exclusively from the point of view of rock mechanics and others from the point of view of chemical interactions between shales and fluids (Wu et al. 1993; Corrêa and Nascimento 2005). Based on the second approach, a variety of water-based drilling fluids and non-aqueous fluids have been applied; meanwhile, many types of wellbore stabilizers have been developed. These wellbore stabilizers have been classified into several groups, including inorganic salts, formate, polymers with special shale affinity, asphalts, sugars and sugar derivatives, glycerol, polyalcohol, and silicates (Van Oort 2003; Guo et al. 2006; Khodja et al. 2010; Jiang et al. 2011; Zhong et al. 2011). Among of them, asphalts as 
one type of cheap and effective stabilizer can improve wellbore stabilization mainly through plugging or sealing, and they have been divided into four varieties according to modification methods: natural asphalt (no modification, mined from deposit), oxidized asphalt (oxidation by air blown to heighten softening point), sulfonated bitumen (changed into asphalt sulfonate partly to enhance water solubility), and emulsified asphalt (oil in water emulsion to improve dispersion in the drilling fluid and adsorption on the rock surface) (Sharma and Wunderlich 1987; Wang et al. 2005). All types of emulsified asphalts are mostly produced by shearing and thinning a mixture of asphalt, water, and emulsifier using an emulsion machine or a colloid mill. Ionic surfactants are often used as emulsifier, so the emulsified asphalt droplets are mostly charged and possess an electric double layer structure, according to the Stern model (Xie et al. 2005; Fan et al. 2014). Cationic emulsified asphalts have taken the place of anionic ones in drilling fluids to promote inhibition and adsorption (Shi et al. 2003; Wang and Xia 2006). In this paper, a novel cationic emulsified asphalt was investigated to overcome serious instability problems during drilling hydratable shale formations. It had good colloidal stability, particle size distribution, compatibility, sealing property, and flexible adaptability.

\section{Experimental}

\subsection{Materials}

Asphalts used in this study are listed in Table 1. 0\# diesel was purchased from the Ruida Chemical Co. Ltd., Jinan, China. Liquid protecting agent (sorbitanoleate) and emulsifier (stearyltrimethyl ammonium chloride) were purchased from the First Chemical Co., Ltd., Dongying, China. Cationic polymer was supplied by the Nur Chemical Co. Ltd., Dongying, China. Hydrochloric acid, calcium chloride, potassium chloride, calcium oxide, and sodium hydroxide were all of analytical grade and commercially available. Sodium bentonite was purchased from the Boyou Bentonite Group Co., Ltd., China. Calcium bentonite was obtained from the Weifang Huawei Bentonite Group Co., Ltd., China, following the American Petroleum Institute (API) standard. Shale samples were taken from the Santai oilfield, Xinjiang, China. ZX-3 (cationic emulsified asphalt), DYFT-1 (sulfonated asphalt), SDT-108 (amphoteric polymer), CPAM (cationic polyacrylamide), SD-101 (sulfonated phenolic resin), CXB-3 (sulfonated lignite), PMHA-2 (amphoteric polymer), NPAN (polyacrylonitrile ammonium), SMP1 (sulfonated phenolic resin), SPNH (sulfonated lignite), XY-27 (polymer viscosity reducer), and SD-506 (liquid lubricant) were of technical grade sourced from the Drilling Technology Research Institute of the Western Drilling Engineering Company, Xinjiang, China. Sand filter disks were purchased from the Geological Science Research Institute of Shengli Oilfield, Dongying, China.

\subsection{Preparation of an electropositive wellbore stabilizer (EPWS)}

Preparation of an electropositive wellbore stabilizer involved the following steps: after the addition of $0 \#$ diesel $(80 \mathrm{~g})$ in a $500-\mathrm{mL}$ three-neck flask, the diesel was heated to $115{ }^{\circ} \mathrm{C}$ using a thermostat oil bath, adding plant asphalt A (20 g), petroleum asphalt B (20 g), asphalt C (40 g), and asphalt D (40 g) successively while stirring at $120 \mathrm{rpm}$. The stirring speed was then adjusted to $500 \mathrm{rpm}$, and the mixture was heated to $124{ }^{\circ} \mathrm{C}$. The temperature was lowered to $95{ }^{\circ} \mathrm{C}$ after asphalts were dissolved completely (about $30 \mathrm{~min}$ ), then the liquid protecting agent $(12 \mathrm{~g})$, emulsifier $(6 \mathrm{~g})$, and calcium oxide $(7 \mathrm{~g})$ were added together with deionized water $(55 \mathrm{~g})$, stirring for $30 \mathrm{~min}$ at $95{ }^{\circ} \mathrm{C}$. The concentrated hydrochloric acid $(12 \mathrm{~g})$ was added, stirring for $40 \mathrm{~min}$ at $95{ }^{\circ} \mathrm{C} ; 20 \mathrm{wt} \%$ calcium chloride solution (45 g), and $1 \mathrm{wt} \%$ cationic polymer solution (33 g) were finally added to the mixture, stirring for $20 \mathrm{~min}$ at $95{ }^{\circ} \mathrm{C}$. Then stirring was stopped, and the temperature was lowered to no more than $55^{\circ} \mathrm{C}$. An electropositive wellbore stabilizer (EPWS) was finally obtained with pour-out of the oil in water emulsion from the three-neck flask. A schematic view of the asphalt emulsion is shown in Fig. 1.

\subsection{Characterization and evaluation}

\subsubsection{Zeta potential and particle size distribution measurements}

Zeta potentials and particle size distributions of test solutions were measured with a Zetasizer 3000 (Malvern
Table 1 Asphalts and their softening points

\begin{tabular}{lcl}
\hline Sample & Softening point, ${ }^{\circ} \mathrm{C}$ & Source \\
\hline Plant asphalt A & 51.7 & Wanshun Chemical Factory \\
Petroleum asphalt B & 78.4 & BEFAR GROUP \\
Asphalt C & 105.5 & Wantong Petrochemical Co., Ltd. \\
Asphalt D & 131.0 & Wantong Petrochemical Co., Ltd. \\
\hline
\end{tabular}




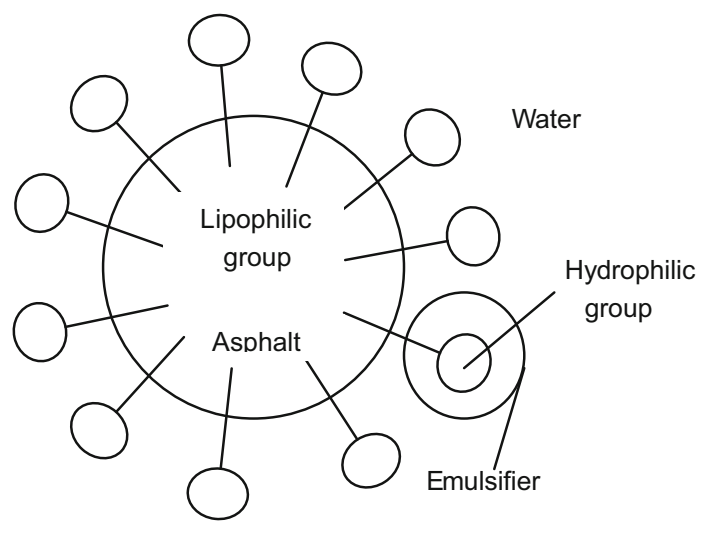

Fig. 1 Schematic view of the asphalt emulsion

Instrument, United Kingdom) (Fadaie et al. 2010). The equipment was turned on and preheated for $15 \mathrm{~min}$. Then a diluted emulsion was added, and the particle size was measured. A total of $5 \mathrm{~mL}$ of the diluted emulsion were injected into the sample container, and the Zeta potential was determined.

\subsubsection{Stability test}

The stability of colloid, foam, and suspension was quantitatively evaluated with a Turbiscan stability analyzer (Formulation Company, France) (Wiśniewska 2010; Kang et al. 2011).

\subsubsection{Fabric analysis}

Some of shale fragments were first ground into powder. The diameter of some of them was less than $150 \mu \mathrm{m}$, and the others were no bigger than $58 \mu \mathrm{m}$.

$\mathrm{X}$-ray diffraction (XRD) analysis was performed on $30 \mathrm{~g}$ of powdered shale sample (smaller than $58 \mu \mathrm{m}$ ) with an X-ray diffractometer (Rigaku D/max-IIIA, Japan) (Wang et al. 2009). A scanning electron microscope (Hitachi, S-4800) was used to observe the microstructure of the fresh appearance of several fragments (Klaver et al. 2012).

\subsubsection{Shale dispersion}

In this test, $50 \mathrm{~g}$ of shale cuttings $(2-5 \mathrm{~mm})$ was added to the test slurry in a conventional fluid cell. Then the fluid cell with cuttings was hot rolled in a conventional roller oven at different temperatures $\left(77,100\right.$, and $\left.120^{\circ} \mathrm{C}\right)$ for $16 \mathrm{~h}$. After hot rolling, the cuttings were screened through a 1-mm size sieve and washed with tap water. After drying, the amount and percent recovered cuttings were determined (Zhong et al. 2012).

\subsubsection{Shale swelling}

A total mass of $10 \mathrm{~g}$ powders were added to a mold and compressed at $15 \mathrm{MPa}$ for $5 \mathrm{~min}$ to prepare a core sample. The height of the core sample was measured and recorded as $H$. Then the mold was fixed onto a linear swell meter (NP-02A, Haitongda Company, China), the heights of the core sample were recorded $8 \mathrm{~h}$ after the test liquid had been added to the sample container.

\subsubsection{Shale stability index}

Shale stability index (SSI) values were determined to define the surface conditions of shale samples before and after exposure to test fluids. 180-250 $\mu \mathrm{m}$ shale particles were mounted in a holder and compressed. Then the hardness of shale samples was measured with a penetrometer before and after exposure to the test fluids.

\subsubsection{Compatibility evaluation}

The test slurry was a mixture (w/v) of sodium bentonite (2\%, $3 \%, 4 \%, 5 \%, 6 \%$, or $7 \%$ ), $0.3 \%$ NPAN, $0.3 \%$ SDT-108, $3 \%$ CXB-3, $3 \%$ SD-101, $0.5 \% \mathrm{CaCl}_{2}, 1 \%$ SD-506, $0.3 \% \mathrm{XY}-27$, inhibitors $(3 \% \mathrm{KCl}, 3 \% \mathrm{ZX}-3$, $3 \%$ EPWS separately), and deionized water. The mixture was stirred for $25 \mathrm{~min}$ at a high speed of 10,000 rpm and then aged for $24 \mathrm{~h}$ at room temperature. The base slurry was composed of $4 \%$ (w/v) calcium bentonite, $3 \%$ EPWS and fluid loss agents (1\% SDT-108, $1 \%$ PMHA-2, $0.3 \%$ CPAM, $0.3 \%$ NPAN, $3 \%$ SMP-1, $3 \%$ SD-101, $3 \%$ SPNH and $3 \%$ CXB-3, respectively), and deionized water. This slurry was also stirred for $20 \mathrm{~min}$ at $10,000 \mathrm{rpm}$ and then aged for $24 \mathrm{~h}$ at room temperature.

Aging experiments of muds were carried out in a XGRL-4 type rolling oven at $150{ }^{\circ} \mathrm{C}$ for $16 \mathrm{~h}$. Mud properties were characterized before and after aging. According to API recommended practice of standard procedures (Recommended Practice 1988), the rheological parameters were calculated from 600 and $300 \mathrm{rpm}$ readings, which were measured with a ZNN-D6 six type speed viscometer.

API filtration of each slurry was evaluated with a ZNS2A filter press under a pressure of $689.5 \mathrm{kPa}$ for $30 \mathrm{~min}$.

\subsection{Investigation of anti-sloughing mechanism}

The particle size distribution of the test mud containing $4 \%$ (w/v) sodium bentonite, $0.3 \%$ NPAN, $0.3 \%$ SDT-108, $3 \%$ CXB-3, $3 \%$ SD-101, $0.5 \% \mathrm{CaCl}_{2}, 1 \%$ SD-506, $0.3 \%$ $\mathrm{XY}-27$, and inhibitors $(3 \% \mathrm{KCl}, 3 \% \mathrm{ZX}-3,3 \%$ EPWS separately) was measured with a Bettersize 2000 laser particle size analyzer. Sealing performance of the test mud was evaluated using PPA-2A permeable plugging apparatus at 
3.5 MPa for $30 \mathrm{~min}$. The HTHP filtrate of each mud was tested using a GGS42-2 high pressure high temperature filter tester at a pressure difference of $3.5 \mathrm{MPa}$ and different temperatures $(70,80,90,100,110,120,130,140$, and $150{ }^{\circ} \mathrm{C}$ ) for $30 \mathrm{~min}$. The wettability of samples was determined from contact angle measurements by a JC2000D5M contact angle meter using plate-like shale cores.

\section{Results and discussion}

\subsection{Characterization}

Particle size distribution of ZX-3 and EPWS is presented in Fig. 2. The EPWS particles averaged $507 \mathrm{~nm}$ in diameter, ranging from 350 to $900 \mathrm{~nm}$. Similar particle distribution was observed for cationic emulsified asphalt ZX-3, and the particles ranged from 700 to $1250 \mathrm{~nm}$ with an average of $844 \mathrm{~nm}$. This indicates that EPWS was a more stable and better dispersing emulsion.

It can be seen from Fig. 3 that the Zeta potential of ZX-3 ranged from 25 to $70 \mathrm{mV}$ with an average of $50 \mathrm{mV}$, while that of EPWS ranged from 30 to $75 \mathrm{mV}$ and averaged $54 \mathrm{mV}$. The higher the positive Zeta potential of the emulsified asphalt, the stronger inhibition it would have by compressing diffuse double layers, adsorption onto the surfaces of clay and rock through electrostatic attraction, and worse compatibility with other additives and bentonite base slurry, because they are negatively charged, leading to poor stability and difficulty in controlling the viscosity and filtration. So the Zeta potential of EPWS was adjusted to

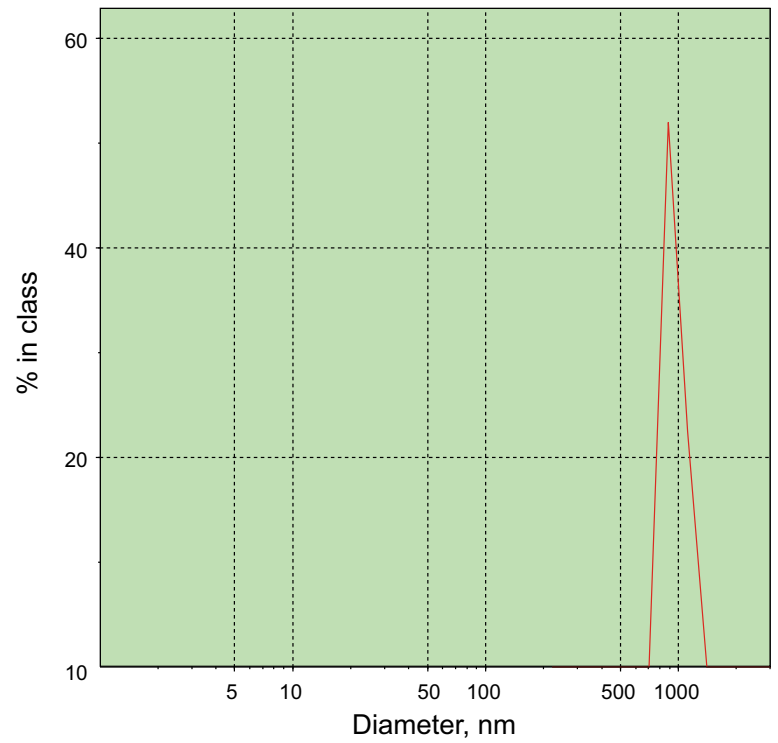

(a) about $55 \mathrm{mV}$ to provide the stronger inhibition and the better compatibility at the same time.

The colloidal stability of the emulsified asphalt affects its storage and dispersion in drilling fluids. The colloidal stability of ZX-3 and EPWS is shown in Fig. 4. The transmitted and scattered light through the sample was recorded every $24 \mathrm{~h}$. The test curves of ZX-3 and EPWS did not change with time extending for 90 days.

After the infrared scanning test, the samples were kept standing for a long time for further observation. No solidliquid separation was observed for ZX-3 and EPWS after standing for 112 and 147 days, respectively.

Therefore, the EPWS exhibited excellent colloidal stability because the pre-dissolved cationic acrylamide with positive charges was added at the final stage after the oil in water emulsion had been formed ( $\mathrm{Li}$ et al. 2012; Zhao et al. 2012).

\subsection{Inhibition}

\subsubsection{Fabric and hydration properties of shale samples}

Mineral composition (in wt $\%$ ) of shale samples and the relative abundance of clay minerals (kaolinite, chlorite, illite, and smectite) are listed in Tables 2 and 3, separately. Rock samples from the Shuangfanggou Formation contained dominantly clay minerals $(45.3 \%)$ and quartz $(28.7 \%)$, followed by anorthoclase (15\%), potash feldspar $(7 \%)$, calcite $(6 \%)$, and hematite $(4.3 \%)$. Smectite was the main component of 4 samples $(90 \%-92 \%)$, with an average of $92 \%$, followed by illite $(3 \%-5 \%)$, kaolinite

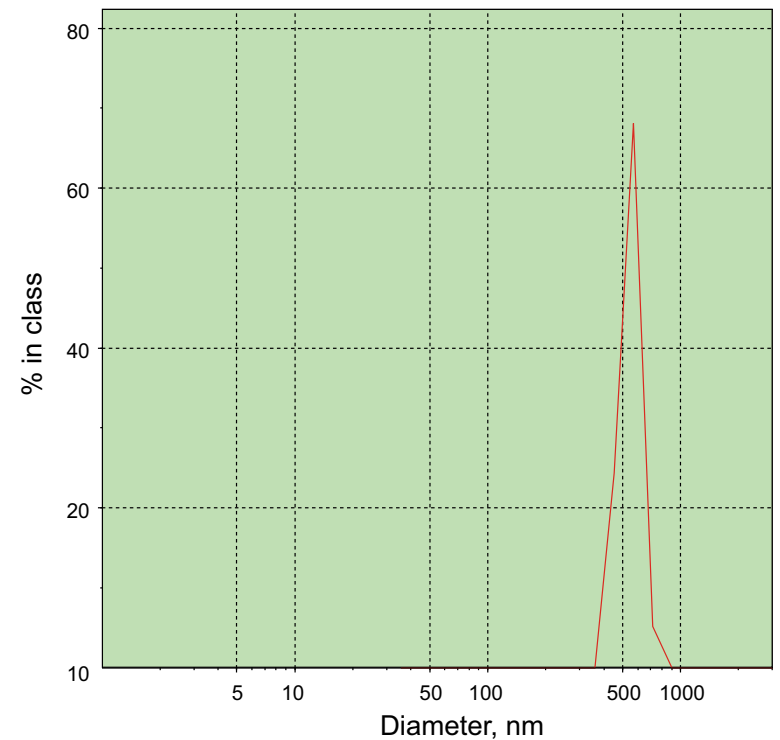

(b)

Fig. 2 Particle size distributions of a ZX-3 and b EPWS 


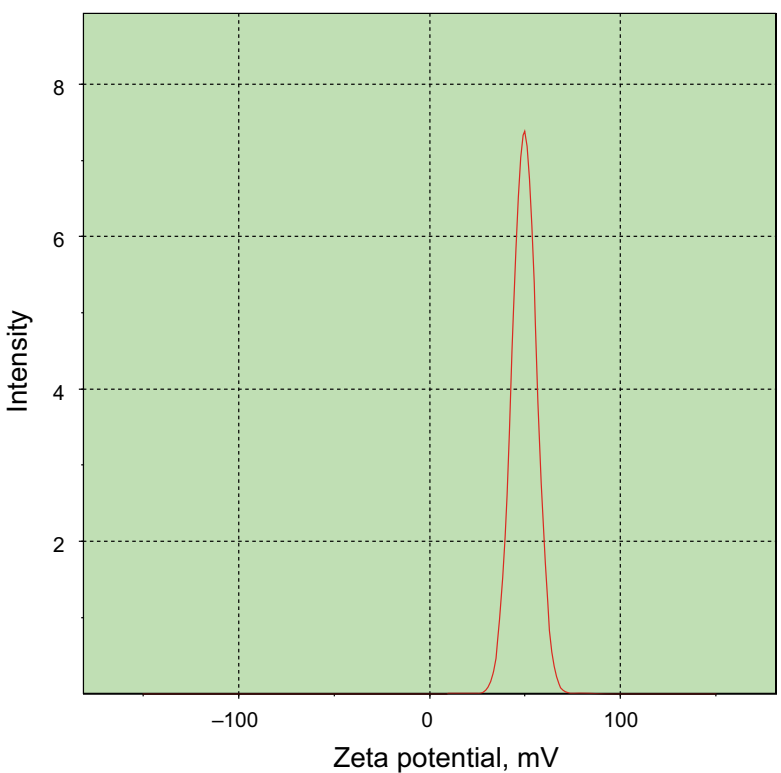

(a)

Fig. 3 Zeta potentials of a ZX-3 and b EPWS
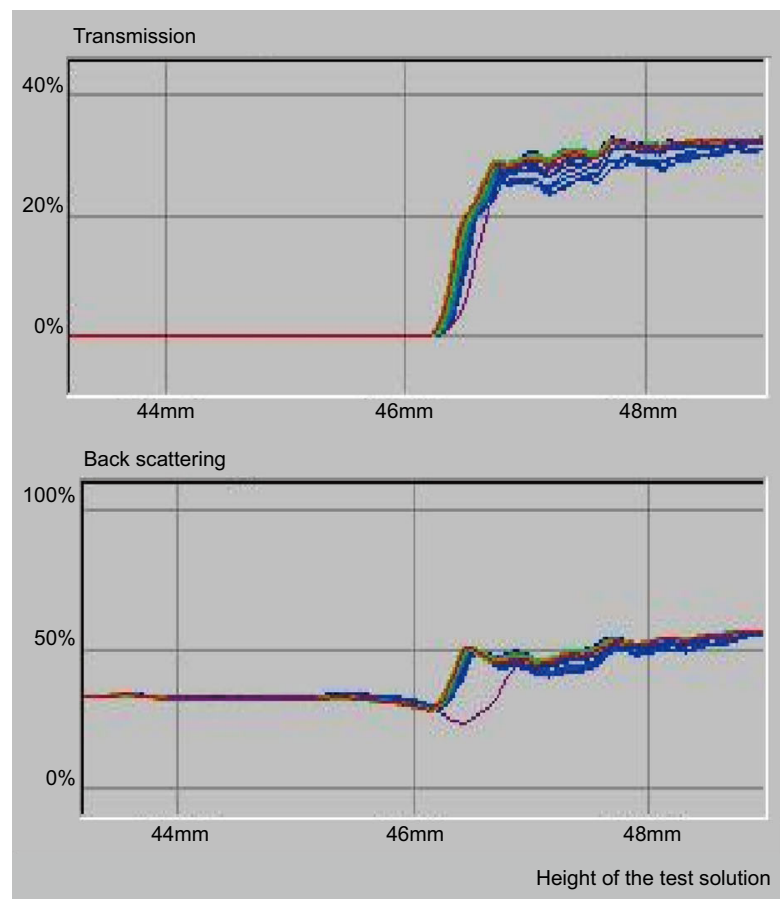

(a)

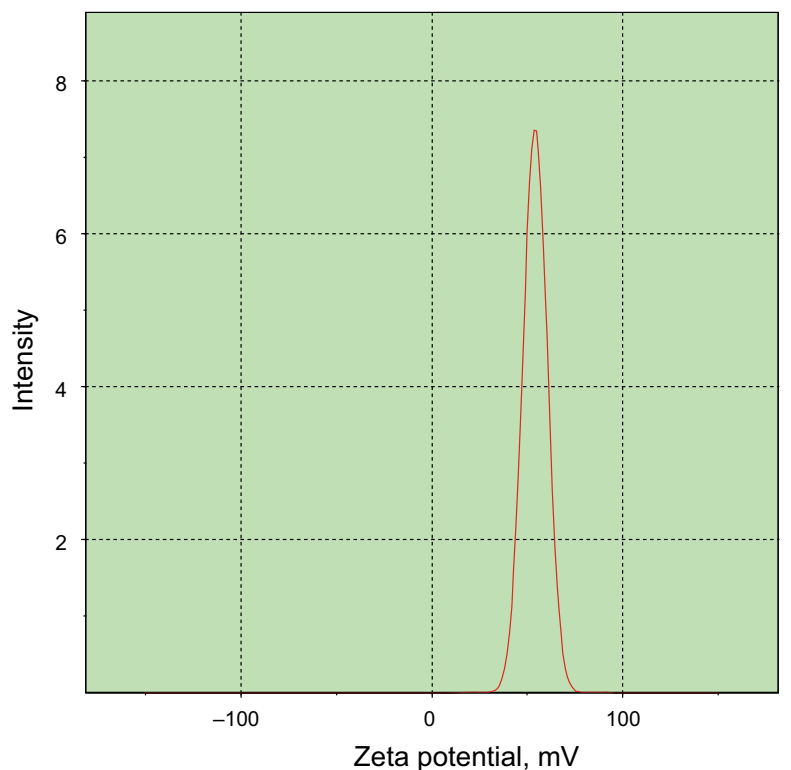

(b)
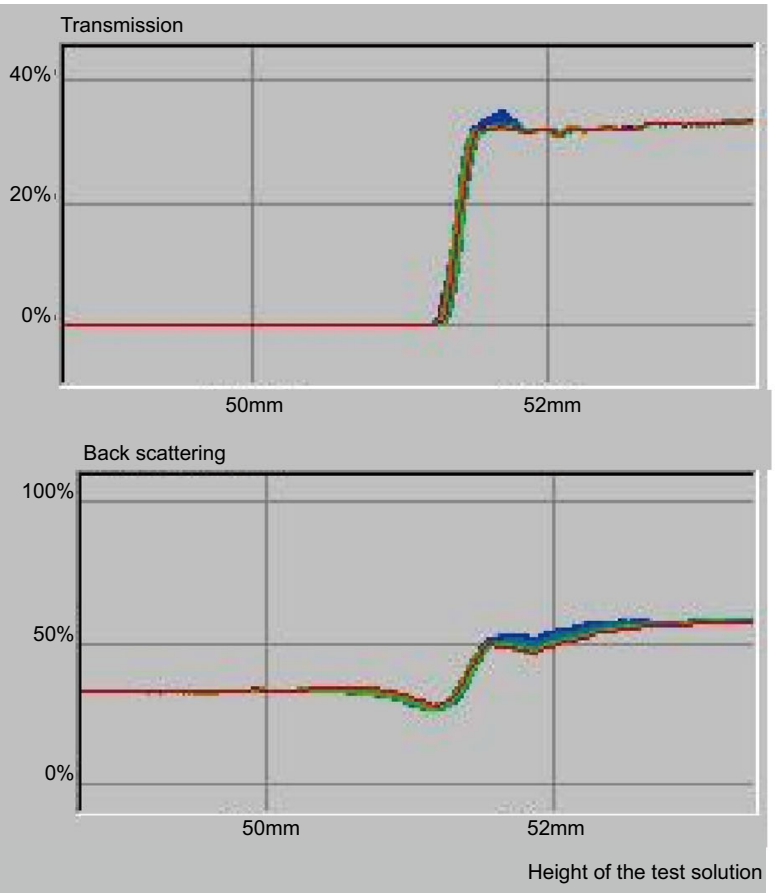

(b)

Fig. 4 Colloidal stability of a ZX-3 and b EPWS

(2\%-3\%) and chlorite $(1 \%-2 \%)$. High proportions of smectite may lead to severe wellbore instability problems during drilling of this formation due to hydration, swelling, dispersion, and mudding of smectite. The shale sample from the Jiucaiyuan Formation contained only $30 \%$ clay minerals, but which is still mainly composed of smectite, making borehole wall collapse likely.

SEM images of the shale sample from well $T_{1} \mathrm{~s}$ (2334-2337 m) are shown in Fig. 5. It can be seen from images that the microstructure of the shale was loose, and 
Table 2 Mineral composition of shale samples determined by X-ray diffraction

\begin{tabular}{|c|c|c|c|c|c|c|c|c|c|}
\hline Sample & Well name & Formation & Depth, m & Quartz, \% & Potash feldspar, \% & Anorthoclase, $\%$ & Calcite, \% & Hematite, \% & Clay, \% \\
\hline 1 & $\mathrm{~T}_{1} \mathrm{~s}$ & Shuangfanggou & 2053-2058 & 30 & 7 & 16 & & 4 & 43 \\
\hline 2 & $\mathrm{~T}_{1} \mathrm{~s}$ & Shuangfanggou & $2248-2252$ & 27 & 7 & 15 & 6 & 4 & 41 \\
\hline 3 & $\mathrm{~T}_{1} \mathrm{~s}$ & Shuangfanggou & $2334-2337$ & 29 & & 14 & & 5 & 52 \\
\hline 4 & $\mathrm{~T}_{1} 8$ & Jiucaiyuan & 2396 & 36 & 7 & 21 & 6 & & 30 \\
\hline
\end{tabular}

Table 3 Relative abundance of clay minerals

\begin{tabular}{lllll}
\hline Sample & Kaolinite, $\%$ & Chlorite, $\%$ & Illite, $\%$ & Smectite, $\%$ \\
\hline 1 & 2 & 2 & 4 & 92 \\
2 & 2 & 1 & 3 & 94 \\
3 & 3 & 2 & 5 & 90 \\
4 & 4 & 2 & 4 & 90 \\
\hline
\end{tabular}

micro-fractures and micro-pores were developed. The clay minerals were mixed with quartz crystal layers, filling intergranular pores. The micro-fractures and micro-pores supplied channels for invading filtrate and lost circulation of drilling fluids, leading to wellbore instability.

Recovery of shale samples from the Santai oilfield averaged $5.6 \%$, with a range from $4.3 \%$ to $7.4 \%$. This indicates that the shale is easy to hydrate and disperse in water.

Linear swelling of shale samples was between $15.6 \%$ and $18.1 \%$ with an average of $17.3 \%$, indicating that the shale samples have high hydration capacity and swelling performance. The swelling was very high at the initial stage once the shale contacted water, and increased slowly after half an hour up to a final maximum at $8 \mathrm{~h}$ (Fig. 6). Therefore, the instability of shale formations in the Santai

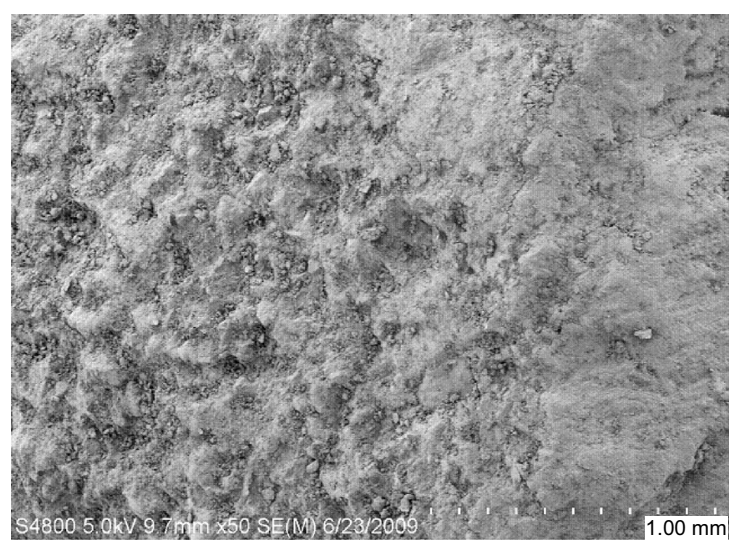

(a)

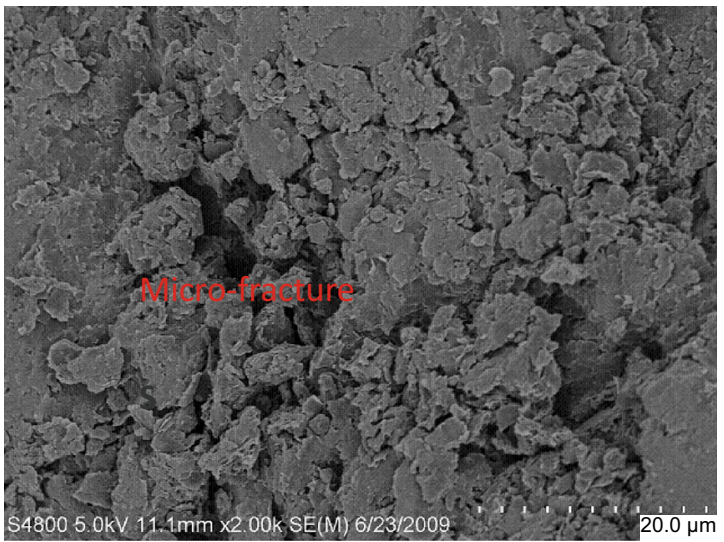

(c)

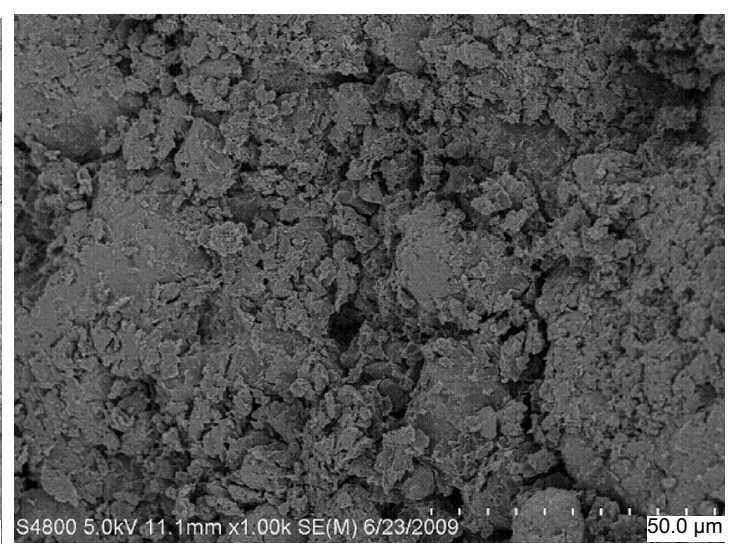

(b)

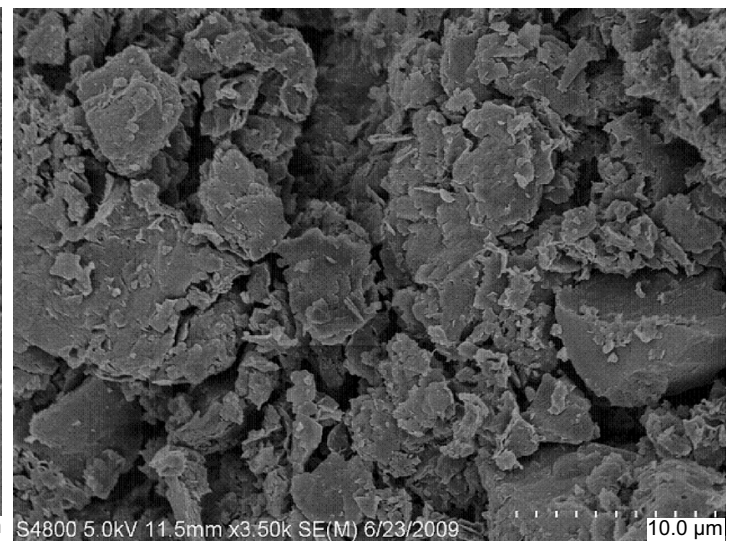

(d)

Fig. 5 SEM images of the shale sample from well $\mathrm{T}_{1} \mathrm{~s}(2334-2337 \mathrm{~m})$. a Outline; b Micro-fractures and pores; c Micro-fractures and pores; d Clay minerals mixed up with quartz 


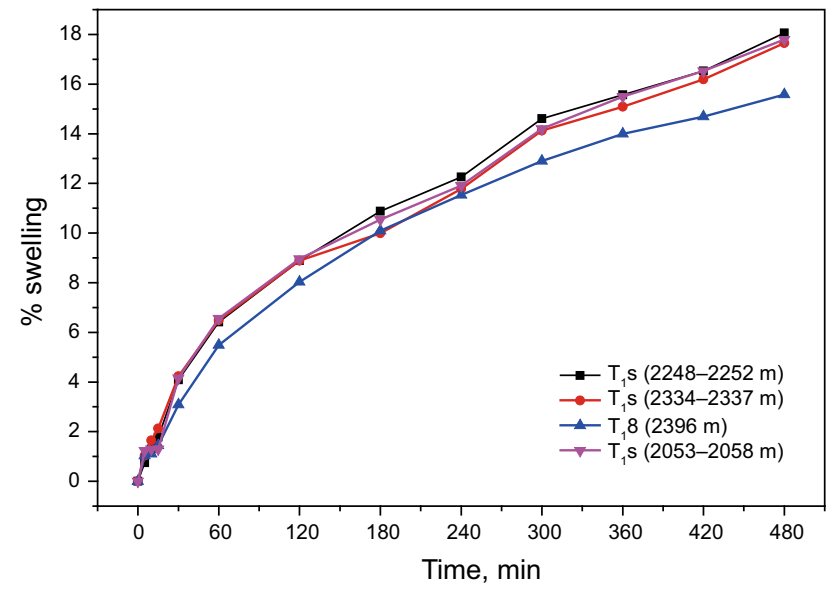

Fig. 6 Linear swelling of shale samples from the Santai oilfield

oilfield attributes to the micro-fractures and pores in shales, which provides enough channels and space for invasion of drilling fluids, and the strong hydration of shales. To prevent sloughing of this formation during operations, excellent inhibition and sealing characteristics of drill in fluids are required.

\subsubsection{Comparative assessment of inhibition}

As shown in Fig. 7, $10 \% \mathrm{KCl}$ solution, $3 \% \mathrm{ZX}-3$ suspension, and $3 \%$ EPWS suspension all exhibited better

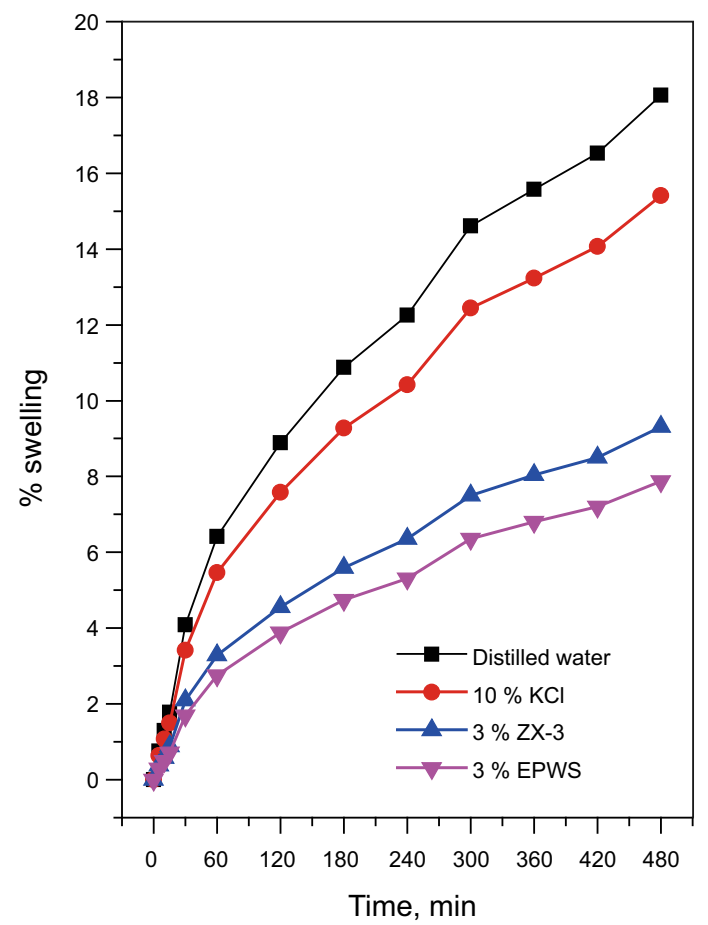

(a) capacity to inhibit swelling of shale powders and sodium bentonite compared to distilled water. The linear swelling of shale powders from well $\mathrm{T}_{1} \mathrm{~s}(2248-2252 \mathrm{~m})$ within $8 \mathrm{~h}$ was reduced from $18.1 \%$ to $15.4 \%$ for $10 \% \mathrm{KCl}, 9.3 \%$ for $3 \% \mathrm{ZX}-3$ and $7.9 \%$ for $3 \%$ EPWS. The linear swelling of sodium bentonite was decreased from $38.4 \%$ to $33.0 \%$ by $10 \% \mathrm{KCl}$, to $20.5 \%$ by $3 \% \mathrm{ZX}-3$ and to $17.9 \%$ by $3 \%$ EPWS. Moreover, the swelling of shale powders and sodium bentonite at the initial stage was clearly lowered by ZX-3 and EPWS. Among evaluated samples, the EPWS had the best capacity to inhibit hydration and swelling of shales.

Experimental results of the shale recovery and SSI measurements are presented in Fig. 8. The recovery and the SSI of samples in distilled water were very low, indicating easily hydration and dispersion in water and poor stability of the shale formation. The shale recovery and SSI reduced with an increase in temperature, suggesting that at high temperatures shale hydration would be promoted thus causing shale deterioration and wellbore instability. The recovery of shale particles was increased from $7.1 \%$ to $29.9 \%$ for $10 \% \mathrm{KCl}$, to $35.7 \%$ for $3 \% \mathrm{ZX}-3$, and to $62.1 \%$ for $3 \%$ EPWS at $77{ }^{\circ} \mathrm{C}$, while the SSI of shale powders rose from 24.1 to $40.9 \mathrm{~mm}$ for $10 \% \mathrm{KCl}$, to $53.7 \mathrm{~mm}$ for $3 \% \mathrm{ZX}-3$, and to $65.4 \mathrm{~mm}$ for $3 \%$ EPWS. The recovery and SSI of shale samples were also increased significantly at 100 and $120{ }^{\circ} \mathrm{C}$ after adding $\mathrm{KCl}, \mathrm{ZX}-3$,

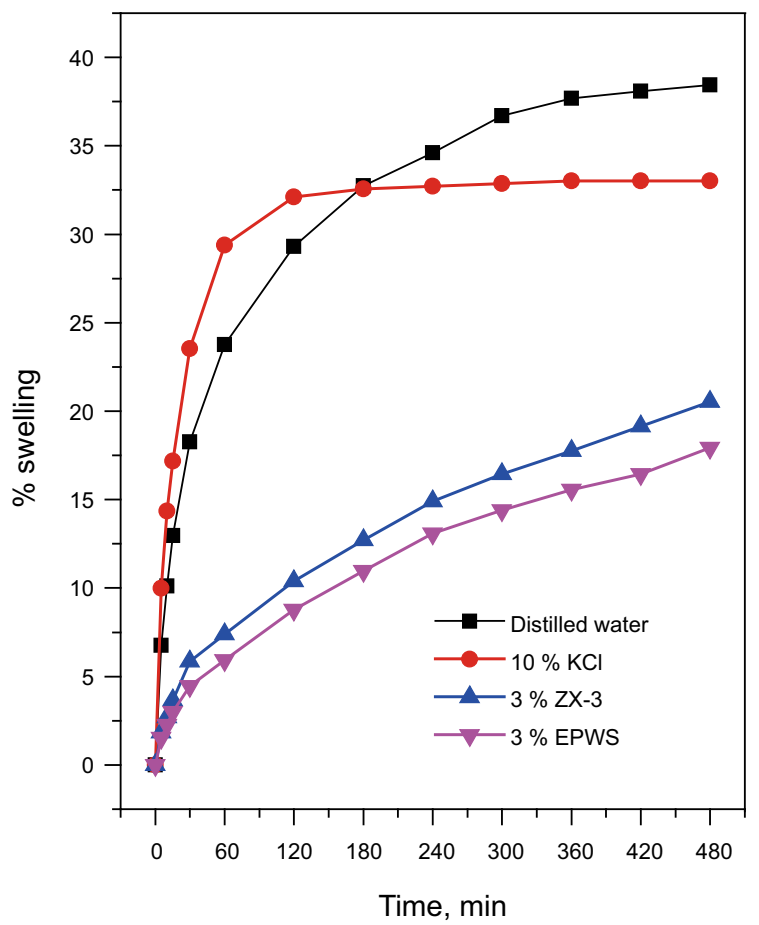

(b)

Fig. 7 Results of linear swelling tests. a Shale powders; b Sodium bentonite 


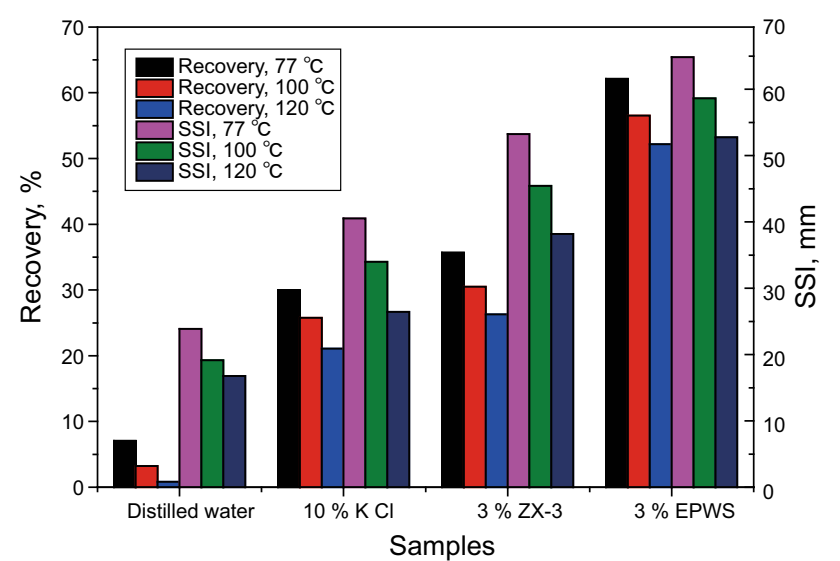

Fig. 8 Results of shale recovery and SSI measurements

and EPWS. The EPWS exhibited superlative performance in depressing hydration and improving wellbore stability at 77,100 , and $120^{\circ} \mathrm{C}$, corroborating its flexible adaptability to temperature.

\subsection{Compatibility}

Figure 9 reveals the effect of inhibitors on the plastic viscosity and filtration of drilling fluids containing different

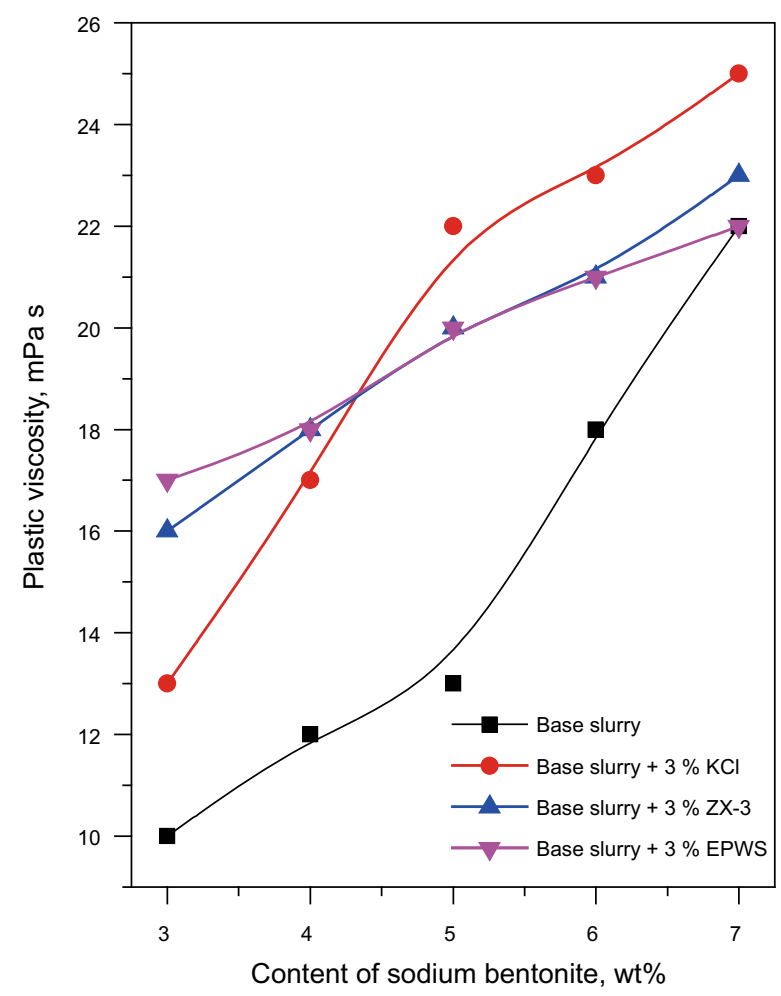

(a) amounts of sodium bentonite. Addition of $3 \% \mathrm{KCl}, 3 \%$ ZX-3, or $3 \%$ EPWS to the base slurry increased the plastic viscosity of the slurry in that they compressed the diffuse double layers of clay particles, leading to more face to edge connections in the system (Fig. 9a). The plastic viscosity of the slurry containing $3 \%$ EPWS increased slowly as the content of sodium bentonite increased from $3 \%$ to $7 \%$, showing its good compatibility with bentonite. The filtrate from the base slurry was smaller before adding $3 \% \mathrm{KCl}$, $3 \% \mathrm{ZX}-3$, or $3 \%$ EPWS and reduced with an increase in the bentonite content (Fig. 9b). The effect of EPWS on filtration of the slurry containing different contents of sodium bentonite was lesser than $\mathrm{ZX}-3$ and $\mathrm{KCl}$, corroborating its preferable compatibility with bentonite and plugging property in drilling fluids.

It could be seen from Table 4 that SDT-108, CPAM, SD-101, and CXB-3 exhibited better ability to control fluid loss among the evaluated samples. SDT-108 is an amphoteric polymer with an intermediate molecular weight of about 1,000,000 and good salt tolerance. CPAM is one type of cationic polyacrylamide with a cationic degree of $5 \%$. SD-101 is a sulfonated phenolic resin of a high sulfonation degree, more than $25 \%$, and tolerant to saturated salt water. CXB-3 is a sulfonated lignite, and tolerant to salt. It can be concluded that the EPWS is compatible with

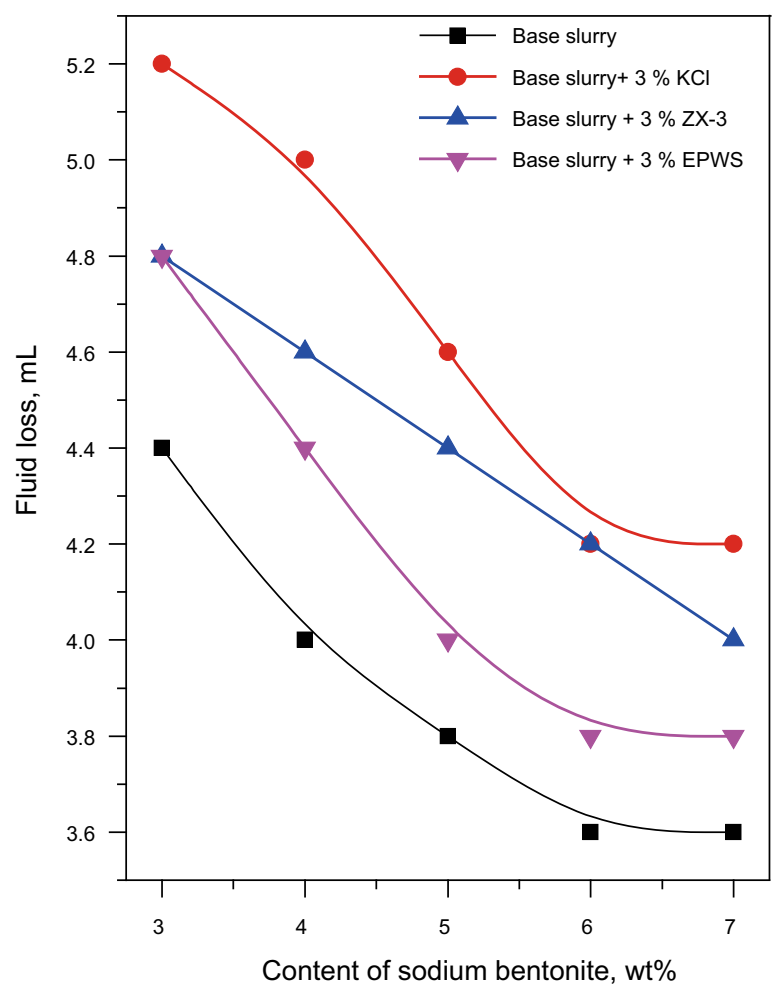

(b)

Fig. 9 Effect of inhibitors on intake capacity of drilling fluids. a Plastic viscosity; b Filtrate 
Table 4 Compatibility evaluation of EPWS with fluid loss agents

\begin{tabular}{|c|c|c|c|c|c|c|c|}
\hline Formula & Test condition & $\theta_{6}$ & $\theta_{3}$ & $\begin{array}{l}\text { Apparent viscosity, } \\
\mathrm{mPa} s\end{array}$ & $\begin{array}{l}\text { Plastic viscosity, } \\
\mathrm{mPa} \mathrm{s}\end{array}$ & $\begin{array}{l}\text { Yield point, } \\
\mathrm{Pa}\end{array}$ & $\begin{array}{l}\text { Fluid loss, } \\
\mathrm{mL}\end{array}$ \\
\hline \multirow[t]{2}{*}{ Base slurry } & Before aging & 3 & 2.5 & 6 & 4 & 2 & 61 \\
\hline & After aging & 5.5 & 5 & 6 & 3.5 & 2.5 & 96 \\
\hline \multirow[t]{2}{*}{$+1 \%$ SDT-108 } & Before aging & 1 & 0.5 & 12.5 & 9 & 3.5 & 8.2 \\
\hline & After aging & 1.5 & 1 & 19.2 & 17 & 2.2 & 9.2 \\
\hline \multirow[t]{2}{*}{$+1 \%$ PMHA-2 } & Before aging & 12 & 11 & 41 & 18 & 23 & 7.6 \\
\hline & After aging & 3 & 2 & 21.5 & 16.5 & 5 & 10.4 \\
\hline \multirow[t]{2}{*}{$+0.3 \%$ CРAM } & Before aging & 10 & 9 & 23.7 & 13 & 10.7 & 7.6 \\
\hline & After aging & 5 & 4 & 20.7 & 13 & 7.7 & 12 \\
\hline \multirow[t]{2}{*}{$+0.3 \%$ NPAN } & Before aging & 1 & 0.5 & 3 & 2.5 & 0.5 & 17.2 \\
\hline & After aging & 1 & 0.5 & 3.2 & 2.5 & 0.7 & 17.6 \\
\hline \multirow[t]{2}{*}{$+3 \%$ SMP-1 } & Before aging & 1 & 0.5 & 5.2 & 5 & 0.2 & 8 \\
\hline & After aging & 1 & 0.5 & 5.25 & 5 & 0.2 & 9.6 \\
\hline \multirow[t]{2}{*}{$+3 \%$ SD-101 } & Before aging & 1 & 0.5 & 4.5 & 4 & 0.5 & 8.2 \\
\hline & After aging & 1 & 0.5 & 5 & 5 & 0 & 9.2 \\
\hline \multirow[t]{2}{*}{$+3 \% \mathrm{SPNH}$} & Before aging & 1 & 0.5 & 3.7 & 3.5 & 0.2 & 8.4 \\
\hline & After aging & 1 & 0.5 & 4.5 & 4 & 0.5 & 11.4 \\
\hline \multirow[t]{2}{*}{$+3 \%$ CXB-3 } & Before aging & 1.5 & 1 & 5 & 3 & 2 & 7.8 \\
\hline & After aging & 1 & 0.5 & 3.5 & 3 & 0.5 & 10.6 \\
\hline
\end{tabular}

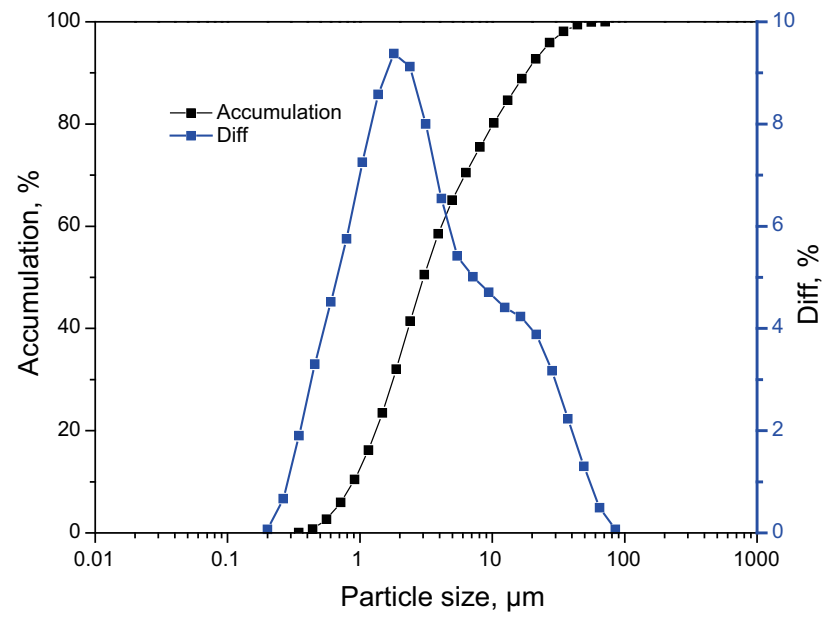

Fig. 10 Particle size distribution of the test slurry containing $3 \%$ EPWS

those additives which are salt tolerant or positively charged.

\subsection{Mechanism of stabilizing the borehole}

\subsubsection{Plugging}

The particle size of the test slurry containing $3 \%$ EPWS ranged from 0.34 to $71.5 \mu \mathrm{m}$, with an average diameter of $3.8 \mu \mathrm{m}$ (Fig. 10). Other characteristic values included $D_{3}$ of $0.739 \mu \mathrm{m}, D_{6}$ of $0.914 \mu \mathrm{m}, D_{10}$ of $1.135 \mu \mathrm{m}, D_{16}$ of $1.468 \mu \mathrm{m}, D_{25}$ of $1.975 \mu \mathrm{m}, D_{75}$ of $10.03 \mu \mathrm{m}, D_{84}$ of $16.12 \mu \mathrm{m}, D_{90}$ of $22.80 \mu \mathrm{m}$. Therefore, the test slurry may penetrate and deposit in the pores and micro-fractures in the loose shale formations, whose micro-fracture and pore diameter ranges from 7.6 to $142 \mu \mathrm{m}$ according the particle bridging rule. A sand filter disk with permeability of $457 \times 10^{-3} \mu \mathrm{m}^{2}$, pore diameter of $6.4-125 \mu \mathrm{m}$ was chosen to evaluate the sealing capacity of the EPWS (Fig. 11a). An external mud cake was formed at the sand filter disk surface during percolating and plugging, with a thickness of $100 \mu \mathrm{m}$ (Fig. 11b). The thickness of the sealing belt near the external mud cake was about $130 \mu \mathrm{m}$, where the inner mud cake was formed. The compacted external mud cake and sealing belt may reduce and prevent the filtrate from invading into the deeper shale formations and retarding pressure transmission. Filtration of the test slurry containing $3 \%$ DYFT-1, $3 \%$ ZX-3, and $3 \%$ EPWS separately was conducted at high temperatures and high pressures (HTHP), and the experimental results are presented in Fig. 12. The HTHP filtrate of the test slurry containing sulfonated asphalt DYFT-1 (softening point, $120{ }^{\circ} \mathrm{C}$ ) decreased at the first half stage to a minimum value of $11 \mathrm{~mL}$ at $100{ }^{\circ} \mathrm{C}$, then increased at the second half stage when the test temperature changed from 70 to $150{ }^{\circ} \mathrm{C}$. When it comes to the slurries containing ZX-3, especially EPWS, the HTHP filtrate increased slowly with an increase in the test temperature. 


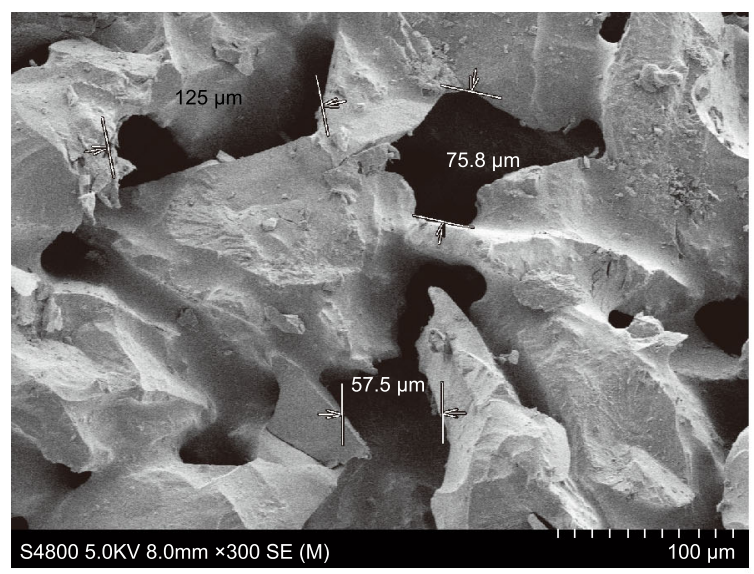

(a)

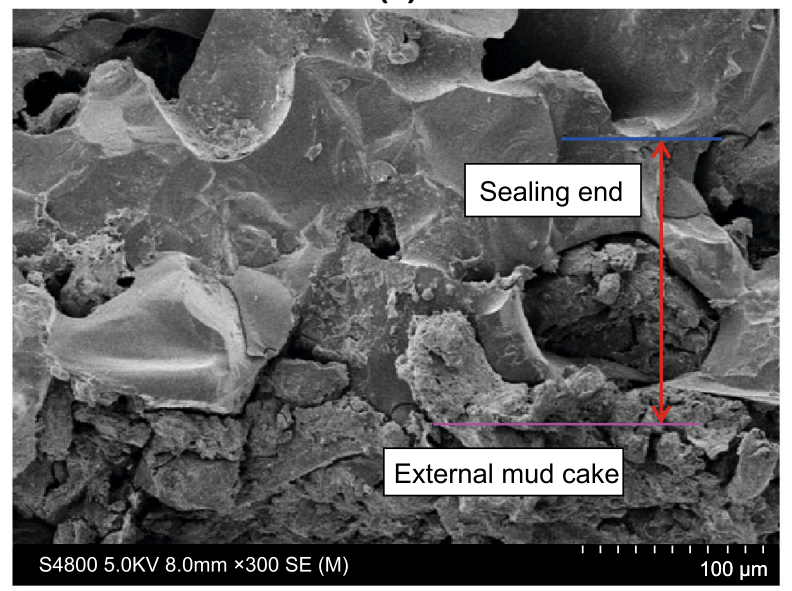

(b)

Fig. 11 SEM images of sand filter disk. a Before plugging; b After plugging

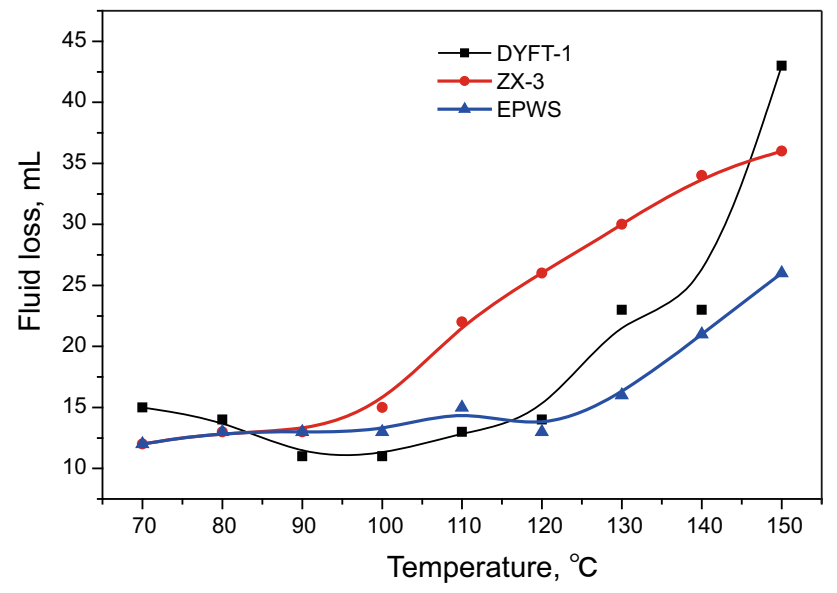

Fig. 12 Effect of temperature on the test slurries containing $3 \%$ DYFT-1, ZX-3, and EPWS separately
The reason for this phenomenon lies in the sealing capacity of the sulfonated asphalt depends on its softening point and optimal plugging performance can be obtained at a temperature about $20^{\circ} \mathrm{C}$ less than the softening point while that of the emulsified asphalt is affected by more factors such as the particle size of emulsion droplets, stability of the emulsion, and softening point of the asphalt used. The temperature generally increases with wellbore extension to deep formations, so the EPWS is more flexible than DYFT-1 and ZX-3 for plugging shale formations in long open-hole intervals.

\subsubsection{Hydrophobic modification of shale surfaces}

Contact angle results are illustrated in Fig. 13. It can be clearly seen that water spreads adequately on the original shale surface with a low contact angle of $7.6^{\circ}$. In contrast, the contact angles of the water droplet on the shale surface modified by suspensions containing DYFT-1, ZX-3, or EPWS were much higher, with the average contact angle of $26.3^{\circ}, 38.6^{\circ}$, and $91.7^{\circ}$, respectively. Hydrophobic performance of the sulfonated asphalt mainly depends on its soluble parts, while that of the emulsified asphalt depends on more factors such as the emulsifier used, emulsion stability, asphalt properties, and the oil phase (diesel was used to prepare EPWS). The aqueous phase in the drilling fluid would be prevented from coming into contact with the shale surface after hydrophobic modification. Therefore, the EPWS could reduce filtrate invasion through modifying its surface wettability, thus inhibiting surface hydration of shales effectively.

\section{Conclusions}

1. Particle size distribution of cationic emulsified asphalt droplets was optimized by dissolving asphalt in diesel and emulsifying it with diesel and water together. Colloidal stability of cationic emulsified asphalt droplets was enhanced through increasing the viscosity of the emulsion using a cationic polymer solution. The Zeta potential of cationic emulsified asphalt droplets was adjusted to a suitable value by selecting the emulsifier and its dosage.

2. Newly synthesized EPWS with an average particle size of $507 \mathrm{~nm}$ and an average Zeta potential of $54 \mathrm{mV}$ could be stable for 147 days, superior to the cationic emulsified asphalt ZX-3 prepared by the conventional method. 


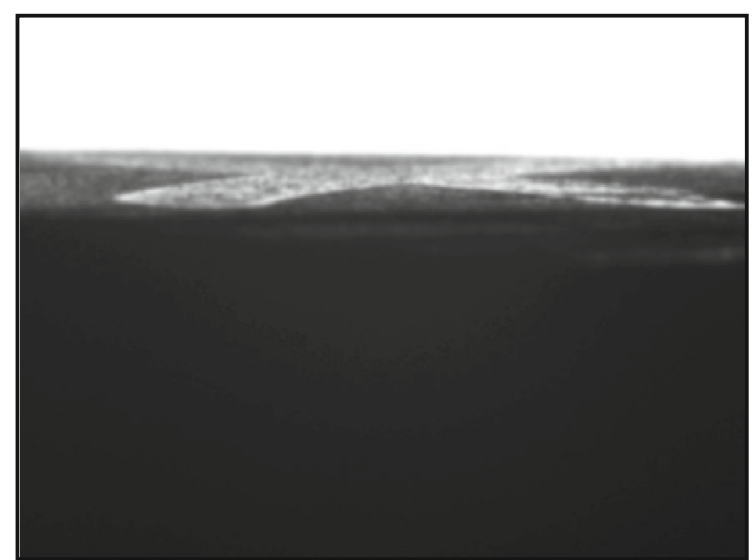

(a)

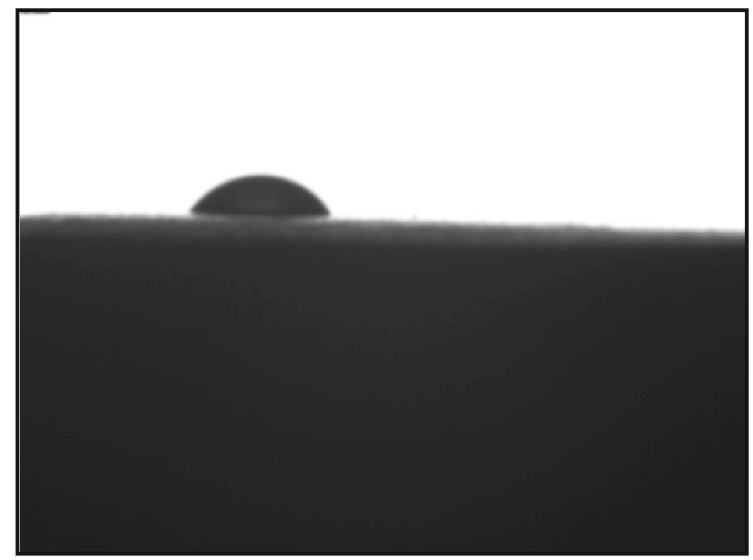

(c)

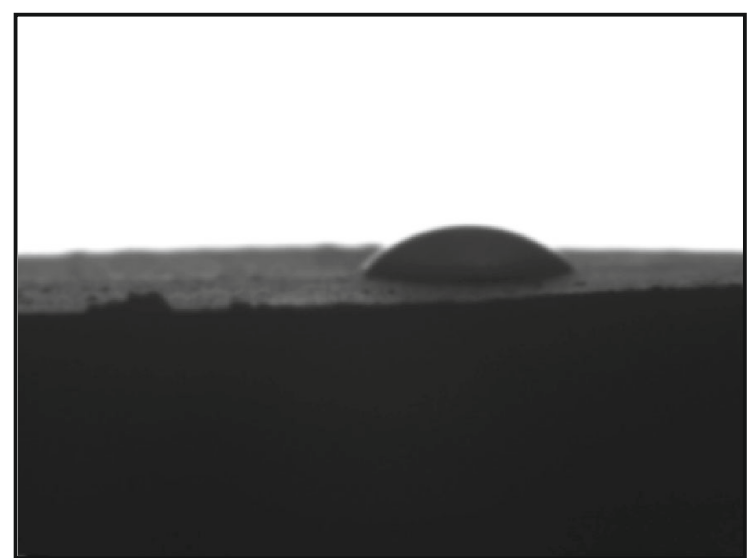

(b)

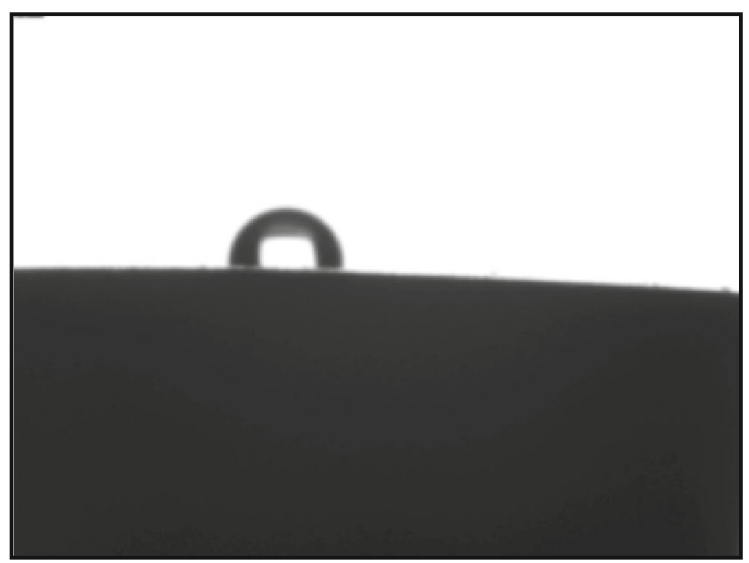

(d)

Fig. 13 Optical images of drops of water on the shale surface. a Original surface; b Modified by $3 \%$ DYFT-1 suspension; c Modified by $3 \%$ ZX-3 suspension; $\mathbf{d}$ Modified by $3 \%$ EPWS suspension

3. The EPWS exhibited better flexible adaptability than ZX-3 and $\mathrm{KCl}$ to temperature at inhibition, sealing capacity, and preferable compatibility with sodium bentonite, salt tolerant, or positive charged additives.

4. The EPWS could plug micro-fractures and pores through forming a tight external mud cake and a sealing belt to retard pressure transmission and prevent filtrate invasion, enhancing hydrophobicity of the shale surface by adsorption to inhibit hydration.

Acknowledgments This work was financially supported by the National Science Foundation of China (No. 51374233), Shandong Province Science Foundation (No. ZR2013EEM032), the Fundamental Research Funds for the Central Universities (No. 13CX02044A) and the Project of China Scholarship Council (201306455021).

Open Access This article is distributed under the terms of the Creative Commons Attribution 4.0 International License (http://creativecommons.org/licenses/by/4.0/), which permits unrestricted use, distribution, and reproduction in any medium, provided you give appropriate credit to the original author(s) and the source, provide a link to the Creative Commons license, and indicate if changes were made.

\section{References}

Corrêa CC, Nascimento RS. Study of shale-fluid interactions using thermogravimetry. J Therm Anal Calorim. 2005;79(2):295-8.

Fadaie S, Kashani MM, Maghsoudipour A, et al. Synthesis of yttria nanoparticles using NIPAM/AAc copolymer. Pigm Resin Technol. 2010;39(4):214-22.

Fan WY, Zhao PH, Kang JQ, et al. Application of molecular simulation technology to emulsified asphalt study. J China Univ Pet. 2014;38(6):179-85 (in Chinese).

Guo JK, Yan JN, Fan WW, et al. Applications of strongly inhibitive silicate-based drilling fluids in troublesome shale formations in Sudan. J Pet Sci Eng. 2006;50(3):195-203.

Hisham TE. Factors influencing determination of shale classification indices and their correlation to mechanical properties. Geotech Geol Eng. 2006;24(6):1695-713.

Huang WA, Qiu ZS, Xu JF, et al. Experimental study on sidewall instability mechanism of oil wells in the western Tuha Oilfield. Acta Pet Sin. 2007;28(3):116-20 (in Chinese). 
Jiang GS, Ning FL, Zhang L, et al. Effect of agents on hydrate formation and low-temperature rheology of polyalcohol drilling fluid. J Earth Sci. 2011;22(5):652-7.

Jiang GC, Xuan Y, Li Y, et al. Inhibitive effect of potassium methylsiliconate on hydration swelling of montmorillonite. Colloid J. 2014;76(4):408-15.

Kang WL, Xu B, Wang YJ, et al. Stability mechanism of W/O crude oil emulsion stabilized by polymer and surfactant. Colloids Surf A. 2011;384(1):555-60.

Khodja M, Canselier JP, Bergaya F, et al. Shale problems and waterbased drilling fluid optimization in the Hassi Messaoud Algerian oil field. Appl Clay Sci. 2010;49(4):383-93.

Klaver J, Desbois G, Urai J, et al. BIB-SEM study of the pore space morphology in early mature Posidonia Shale from the Hils area, Germany. International Journal of Coal Geology. 2012; 103:12-25.

Li HP, Zhao H, Liao KJ, et al. A study on the preparation and storage stability of modified emulsified asphalt. Pet Sci Technol. 2012;30(7):699-708.

Recommended Practice. Standard procedure for field testing drilling fluid. 12th ed. Recommended Practice, vol. 13. Washington, DC: API; 1988. pp 7-9.

Sharma MM, Wunderlich RW. The alteration of rock properties due to interactions with drilling-fluid components. J Pet Sci Eng. 1987;1(2):127-43.

Shi LS, Cao XX, Guo ZN, et al. Factors influencing the breaking time of cationic emulsifier bituminous mixture. J Shandong Univ (Eng Sci). 2003;33(1):97-100 (in Chinese).

Van Oort E. On the physical and chemical stability of shales. J Pet Sci Eng. 2003;38(3):213-35.

Wang $\mathrm{DM}, \mathrm{Xu} \mathrm{YM}, \mathrm{He} \mathrm{DM}$, et al. Investigation of mineral composition of oil shale. Asia-Pac J Chem Eng. 2009;4(5): 691-7.
Wang Q, Zhou YC, Tang YL, et al. Analysis of effect factor in shale wellbore stability. Chin J Rock Mech Eng. 2012a;31(1):171-9 (in Chinese).

Wang Q, Zhou YC, Wang G, et al. A fluid-solid-chemistry coupling model for shale wellbore stability. Pet Explor Dev. 2012b; 39(4):508-13.

Wang SX, Xia SQ. The synthesize and performance research of a new kind of cationic bituminous emulsifier. Pet Asph. 2006;20(4): 30-4 (in Chinese).

Wang XY, Wei J, Li YQ. Study and application of new organic cationic gel drilling fluid. Drill Prod Technol. 2005;27(6):30-4 (in Chinese).

Wiśniewska M. Influences of polyacrylic acid adsorption and temperature on the alumina suspension stability. Powder Technol. 2010;198(2):258-66.

Wu TH, Randolph BW, Huang CS. Stability of shale embankments. J Geotech Eng. 1993;119(1):127-46.

Xie XW, Fu HQ, Hang H, et al. Synthesis of quaternary ammonium cationic emulsifier for asphalt. NianJie. 2005;26(2):39-41 (in Chinese).

Zhang SF, Qiu ZS, Huang WA, et al. A novel aluminum-based shale stabilizer. Pet Sci Technol. 2013a;31(12):1275-82.

Zhang SF, Qiu ZS, Huang WA, et al. Characterization of a novel aluminum-based shale stabilizer. J Pet Sci Eng. 2013b;103: $36-40$.

Zhao $\mathrm{H}$, Li HP, Liao KJ, et al. The anti-aging performance of emulsified asphalt. Pet Sci Technol. 2012;30(2):193-200.

Zhong HY, Qiu ZS, Huang WA, et al. Shale inhibitive properties of polyether diamine in water-based drilling fluid. J Pet Sci Eng. 2011;78(2):510-5.

Zhong HY, Qiu ZS, Huang WA, et al. Poly (oxypropylene)amidoamine modified bentonite as potential shale inhibitor in water-based drilling fluids. Appl Clay Sci. 2012;67-68:36-43. 